THURSDAY, OCTOBER 8,1874

\section{PROFESSOR HUXLEY AT MANCHESTER}

DROF. HUXLEY, whose breadth of view at once I. claims attention for all he utters, has utilised the opportunity afforded him by the opening of the new Medical School at Owens College to call attention to several points the discussion of which at the present time is of the most vital importance.

The rapid growth and increasing importance of Owens College are known to all our readers, and the recent addition of the new Medical School has added still another Faculty to that teaching centre, so that, as Prof. Huxley very properly points out, the College is a University in the old sense in everything but the name. A University in the new sense of course it is not, because it does not yet possess the power of granting degrees. But we inagine that the distinguished men who are directing teaching and research at Owens College can well afford to wait for this privilege, if privilege it be, especially if older foundations set an example of emphasizing this portion of their work to the neglect either of sound practical teaching or the advancement of knowledge which we regard as of still higher importance.

Prof. Huxley, by his approval of the location of the new Medical School side by side with Arts and Science Faculties, has not only brought again to the front the miserable condition of the majority of our Medical Schools, but has called into question the whole policy of Colleges of Science and Institutions for Technical Training. This part of his speech is so important and so connected, and there is so much to ponder over in it, that we give it entire :-

"Your Faculty of Arts speaks for itself; the distinction of many of its members, and the fact that they are authors of works well known and esteemed all over England, and wherever the English language is read, is sufficient to give that Faculty a high position. It certainly would not become me to speak of its operations as if I were a judge of them in any way whatever; but I may be allowed as a person whose pursuits lie elsewhere, and who has the misfortune to be accused sometimes of seeing no merit and desert in anything but his own pursuits, to say that I trust that the position of the Arts Faculty in this institution will never by a hairbreadth or shadow be diminished, but that a sound and thorough training in literature and general knowledge will be regarded henceforward, as very properly it is now, as the essential foundation in the intellectual life of every educated man; and let me say, to no person is such education and such training of greater importance than to us who are called men of science. Our occupations are very engrossing, and they can be pursued with success only by the intensest stress and attention, and we are obliged even to limit ourselves to particular fractions and particular portions of our own study if we are to make any advance therein; and unless we have the good fortune to be trained in early youth to take a broad and general view of the interests of human nature, unless our tastes are disciplined and refined, and unless we are led to see that we are citizens and men before anything else, I say it will go very hard indeed with men of science in future generations, and they will run the risk of becoming scientific pedants when they should be men, philosophers, and citizens. Still less, if possible, can I have anything to say respecting the Faculty of Law, but as regards that of Science, by which, of course, is understood physical science, I can only express my un-

VoL. $x .-N o, 258$ measured satisfaction at the complete-I may almost say magnificent-arrangements provided for the teaching of this subject in this institution. The laboratory of my friend the Professor of Chemistry has, I take it, few parallels; and if the laboratory of my friend the Professor of Physics is not so complete, I am sure it is far better than nine-tenths of such laboratories, and I am certain that those benefactions at which I was looking just now will, before long, enable him to put his establishment on the same footing as to completeness and magnificence as that of his colleague of Chemistry. I understand-indeed I know very well, knowing how much my distinguished friend, Prof. Roscoe, has been in this institution - that he had, I believe, the advantage of being on the spot when the building went on, and although I am sure he is the last man to take any more than his own share, somehow he has got a good deal. But now I come to that which is my proper subject to-day, and that is our Medical School. I have not seen in the course of my experience-I say it deliberately-I have not met with any more efficiently organised institution than you have within the four walls of that Medical School. I have some acquaintance with such institutions, and their interests, and I undertake to say that you will not find better constructed appliances for the teaching of those branches of science which relate to medicine than you will find in that school. Everything has been very carefully considered, and everything has been done which the idea of convenience could suggest, or which efficiency requires to have carried out. Addressing myself now rather to the lay portion of my audience, it may astonish many and puzzle them somewhat to know why so elaborate an apparatus is needed for the teaching of medicine, and why men require to spend so long a period of arduous study in that most important of pursuits. I believe this surprise arises from the prevalence in the general mind of the notion which was once exceedingly common in the philosophical mind, that the human body in general is dependent upon forces and powers which are altogether different from those we find working in other kinds of matter. It is not 200 years since the notion existed that the vital processes of the body were subject to some demon, who kept the body straight, I suppose when in good temper, and let it go wrong when out of sorts; and when it was gravely supposed that there was a broad gulf between the phenomena of inorganic nature and those of life. Now let me say this, that the whole of our modern scientific study of medicine depends upon precisely the contrary assumption -upon the assumption that the living body is a mechanism infinitely more refined, and infinitely more difficult to understand, than our coarse human machinery, but still a mechanism governed by rules and laws which can be discovered and which can be applied and reasonel from, in order to understand its processes. Modern medicine, in fact, is a kind of engineering. It is the attempt to understand the machinery of the body for the purpose of being able to put it right when it goes wrong. I have seen in your great factories in Manchester some of those astonishingly complicated pieces of machinery which seem almost endowed with life, by which the products which make Manchester so famous are produced. Let me put before you the case of the possessor of one of those machines, who, finding that it has gone wrong and that it will not work properly, finds himself, as Sir Robert Peel would have said, with three courses open to him-either that he might sit down and hope that it would get better, and perhaps even offer up his prayers that it might get better; or who should send to the nearest blacksmith and tell him to bring his hammer and bottle of oil, and tap here, or oil there, in the chance of setting the machine right; or should, thirdly, send for some skilled and experienced mechanic who from long study and familiarity with it would be able to judge by the mode of action where it was wrong, and be able to put his finger on the part which 
was broken or injured, and thus be able to set it right. Now, the human body is a machinery which, in complexity, stands to the spinning jenny in the same relation as the spinning jenny stands to a child's windmill. But it stands by the same laws, and those who have to deal with it must be guided by the same reasoning. Sickness is the going wrong of the machinery. Death is the destruction of part of the machinery, and the only way in which that machinery can be set right, if it goes wrong, is not by sitting down and hoping for it, and it is not by sending for the first blacksmith who will administer his purge here and his bleeding there, and who is what we call a 'quack.' I mean a person who is really ignorant of that with which he is dealing, and who yet, nevertheless, presumes to meddle with it. That is the essence of quackery. Or, thirdly, we must send our skilled engineer, who, by the help of what he calls symptoms, finds out what wheel is out of place, what cog is broken, and by his previous knowledge of therapeutics knows in what way it is possible to get this erring wheel or broken pinion into its place again. And it is in order that we may have such skilled engineers to the body that all this great apparatus which you see erected here, and all this long period of study is carried out. I do not know anything which strikes me more forcibly than the progress which this kind of knowledge has made within the last thirty or forty years. . . . I happened to take up to-day the syllabus of your sessional work here, and I turn, not unnaturally, to the class of Practical Physiology and Histology, and on looking over the various doings of this course of instruction, it struck me that thirty years ago, when I began my medical studies, there certainly was nobody in London-nay, nobody in the world-- who could have given you this course of instruction. We had not the instruments which are recessary to carry it out. The whole course of medical study since that time has been completely changed-in the first place, by discoveries made by the use of the microscope, and, in the second place, by that application of delicate instruments to the illustration of the mechanism of the body, which is the very essence and a great part of modern physiology. At that time even organic chemistry was hardly in existence. It is this recognition of the fact that the study of life is essentially a question of applied physics and chemistry which has changed the whole course of our medical studies. It is that which makes elaborate appliances necessary.

The main question raised by Prof. Huxley in these remarks is, in our opinion, really this: Are we in the future to mass our Faculties as they are massed in Germany, or are we to separate them as they are separated in France?

The altogether glorious mental activity of the Germans in the present century is undoubtedly due to the commingling of the teaching of the various Faculties, and to the University teaching universally available. In Germany it may be said that there are no provincial institutions, for the smallest universities are modelled on the largest, and are as perfect, so far as they go. The metropolis is thus carried into the provinces.

Contrast this with the condition of things in France, with its single University and special scientific schools, and where outside Paris there is no institution, so far as we are aware, where all the Faculties exist side by side, and are conducted with equal vigour. Medical Faculty here, Law Faculty there, Arts Faculty somewhere else, and Science Faculty again in another region; such is the condition which is now beingt severely criticised by many of the best minds in France. But it must be remembered that while the whole of France besides
Paris is so lamentably provincial, in Paris itself there are facilities for advancing and distributing knowledge which put London plus Oxford and Cambridge to shame.

In provincia! England we fear it may be said with too much truth that we are at the present moment behind France. It is clear that in Owens College we have an institution which will correct the existing condition of things on the German plan; in such institutions as the Yorkshire College of Science we have attempts to correct it on the French plan, a plan condemned utterly by the most far-seeing men in France itself; while we have not in England the corrective supplied by Paris, considered as a vast centre of teaching and research.

We are glad that Prof. Huxley has called attention to the importance of the step taken by Manchester, and has so clearly stated his idea of the right thing to be done for the advancement of the higher education.

Nor did he neglect to point out the intimate connection that must exist between this and the secondary education before any real progress can be made :-- "You who commence your medical studies should come prepared with the outlines of physics and chemistry as your foundations. One of the great reasons of the backwardness of medical study is that those who come to study are, by reason of the lamentable defects of their common school education, utterly unprovided with a knowledge of what those physical studies mean. I wish to stamp upon your minds, as firmly and as strongly as it is burnt into my own, that all these appliances and all these mechanical aids for the study of medicine are simply thrown away unless they have the foundation of human hard work and clearheadedness to go upon."

Still another point of the most vital importance to the future progress of Science in this country was touched upon; we refer to Prof. Huxley's statement of opinion as to the importance of the Research Scholarships established at Owens College :-

"I notice in these donations and in these sums of money subscribed for the purpose of building and endowing and providing with scholarships this great institution, what appears to me to be a peculiar feature ; at least I know nothing exactly like it anywhere else : and as it appears to me to be a feature of great importance and one which it is desirable to imitate as fast as possible by other educational bodies, you will pardon me if I dilate upon it for a short time. You have two scholarships which differ from the ordinary scholarships in this, that they are rewards not merely for learning, and not merely for careful attention and diligent study of that which the student may learn in the lecture-room or from books, but they are rewards which are given to those who exhibit in some degree that most valuable and most important of all intellectual gifts, the power of advancing truth by the pursuit of original research. I refer to the Dalton Scholarship and the Platt Scholarship. I can conceive no object more important at the present time than that of encouraging original research in science, and the way of doing it, without at the same time doing more harm than good, is one which has come very seriously under my consideration as one of the Royal Commissioners for the Advancement of Science, and I earnestly wish that we could look elsewhere to the solution of that problem by means analogous to those adopted here-I mean to say by private benefactors coming forward with their endowments, which endowments should benefit those only who are engaged in original research. The introduction of scholarships of this kind into the 
early life of young men, when it is so important that their attention should be directed to original research, is a new feature in this institution, and permit me to say, however important the institution may be in other respects, I am not sure that it is not one of the most important of its features."

It will be seen that while Prof. Huxley acknowledged the necessity for the endowment of unremunerative research, speaking as a Royal Commissioner, he acknowledged also that there are difficulties which surround the solution of the question. We are glad of this, because if the things were easy it would certainly not require that the machinery of a Royal Commission such as the one now sitting should be set in motion ; nor, let us add, would it be worth Prof. Huxley's attention. In the fact that the question is a difficult one we see the best justification for the best minds in the country being brought to bear upon it, and we may safely anticipate a satisfactory solution.

\section{THE REPORT OF THE METEOROLOGICAL COMMITTEE}

Report of the Metcorological Committce of the Royal Society for the Year ending December 3I, 1873. (London, I874.)

7 HE proceedings of the Meteorological Committee of I the Royal Society for 1873 are detailed in the above Report. The discussion of the meteorology of the district of the Atlantic Doldrums, known as Square 3, has now been completed, and this piece of work, which the Committee consider may fairly be termed a monograph for the district, will shortly be published. The examination of the eight squares adjacent to Square 3 has already been entered upon. The discussion of the results of Sir J. Ross's Antarctic expedition, from the observations made on board H.M.S. Erebus and Terror in 1840-43 and II.M.S. Pagoda in 1845 , has also been completed and published, and is a paper of considerable value. Another good piece of work done by the Office is the examination, at the request of the Astronomer Royal, of the observations bearing on the meteorology of Kerguelen Island for the month of December, the results of which have been forwarded to those who are now stationed there to observe the transit of Venus.

We are glad to see that an increasing regularity in the receipt of the Weather Telegraphic Reports is notified, and we very cordially join in the regret expressed by the Committee that the Post Office authorities have declined to extcnd the telegraph wires so that a station might be established at Mullaghmore, near Sligo. In consequence of this action or want of action on the part of the Post Office, the Meteorological Office continues to be without daily information along the whole of the impertant and extended line of coast from Valencia to Lough Foyle. We hope that this blank will soon be filled up, and further, that some arrangement will be entered into by which a constant service will be maintained on the west coasts of these islands, and also at the Head Office in London; for until this be carried out, our system of weather telegraphy must, of necessity, not unfrequently fail to give warning of approaching storms. A comparison has been instituted, as in the three previous years, between the warnings issued and the weather experienced on our coasts, with the general result that the total success of warnings for 1873 was $79^{\circ} 2$ per cent. as compared with 80.5 per cent. for 1872 . In 1870 and 1871 the percentages of success were 68.4 and 63.7 respectively. The mean of these four years is nearly the same as that of the last two years when the office was under Admiral Fitzroy's management, but it will be observed that 1872 and 1873 show the largest number of successful warnings.

The restoration of Admiral Fitzroy's system of warnings, so far as to announce in the warning-message the probable direction of the apprehended storm, is a step which, we see at p. $5 \mathrm{I}$ of the "Report on Weather Telegraphy and Storm Warnings, presented to the Congress at Vienna," was strongly urged by the council of the Scottish Meteorological Society upwards of a year ago. The practical restoration of Fitzroy's system has been effected by the Committee, and the change took effect in March last, with, however, the very decided improvement of employing the drum simply to emphasize the warning given by the cone, instead of denoting, as it did originally, "dangerous winds from nearly opposite quarters successively." The Committee have attempted to assign the degree of probability to a storm announced by signal, thus: "Hitherto it has been found that at least three out of five signals of approaching storms (force upwards of 8 Beaufort scale, a fresh gale), and four out of five signals of approaching strong winds (force upwards of 6 Beaufort scale, a strong breeze), have been fully justified." We observe with some interest that the Committee have directed that tentative forecasts should be prepared daily in the office, and compared with the facts experienced subsequently, and that they hope ere very long to be able to afford the public the benefit of the information. For the successful development of the important question of weather probabilities, it will be necessary that the Committee investigate weather changes over a much wider area than is covered by the daily weather charts. In this direction, the reports begun to be received during 1873 from Sweden and Denmark will prove to be of considerable utility ; but for the success of the experiment it will be necessary that daily reports be also received from points in the north-west of Russia, and in Germany, Austria, and Switzerland.

The anemometrical returns from Bermuda for four years have been published. These observations, and similar observations made at Sandwich, Orkney, previously published by the Committee, have been discussed by a method which cannot be recommended. The results are worth little, and altogether inadequate to the expense incurred in their discussion. The discussion of no meteorological data at all approaches in difficulty that of wind observations, and it is necessary at the outset to apprehend the difficulties to be overcome.

In several cases the language used in the Report is inexact and tends to mislead. Thus an excess of high winds on the coast of Scotland during 1873 , and a deficiency on the coasts further south, are stated to be explained by the circumstance that in 1873 "the paths of the storm centres lay to the northward of the British Isles, so that our stations felt the barometrical and other meteorological disturbances, but were not exposed to the full force of the wind." Now, as is pretty well known among 